\title{
Review: amisulpride is effective and safe for schizophrenia
}

\author{
Leucht S, Pitschel-Walz G, Engel RR, et al. Amisulpride, an unusual "atypical" antipsychotic: a meta-analysis of \\ randomized controlled trials. Am J Psychiatry 2002 Feb;159:180-90.
QUESTION: In patients with schizophrenia, is amisulpride effective and safe for treating symptoms?

\section{Data sources}

Studies were identified by searching Medline and Current Contents (to April 2000), scanning reference lists, and contacting the manufacturer of amisulpride.

\section{Study selection}

Studies were selected if they were randomised controlled trials that compared amisulpride with conventional antipsychotics and/or placebo in patients with schizophrenia.

\section{Data extraction}

Data were extracted on patients, drug regimens, study characteristics, and outcomes (including mean change from baseline on the Brief Psychiatric Rating Scale [BPRS] and the Scale for the Assessment of Negative Symptoms; extrapyramidal side effects (EPS) [number of patients needing $\geqslant 1$ dose of antiparkinsonian medication]; and dropouts).

\section{Main results}

18 studies (2214 patients) met the selection criteria Study duration ranged from 3 weeks to 1 year (mean 12 wks). Patients were mostly men in their 30 s with moderate to severe schizophrenia (mean duration 3-37 y). Comparators were usually haloperidol and placebo; 4 studies compared amisulpride with flupentixol, perazine, and fluphenazine. Amisulpride led to a greater mean reduction in BPRS score from baseline than conventional antipsychotics in acutely ill patients (table). In patients with persistent, predominantly negative symptoms, amisulpride was better than placebo (but not conventional antipsychotics) for mean change in negative symptoms (table). In patients with acute exacerbations, amisulpride led to a greater mean change in negative symptoms relative to conventional antipsychotics (table). Amisulpride was better than conventional antipsychotics but was not different from placebo (which was compared with low dose amisulpride, $50-300 \mathrm{mg} / \mathrm{d}$ ) for use of antiparkinsonian drugs (table). In acutely ill patients, fewer patients treated with amisulpride than with conventional drugs dropped out (table). In patients with predominantly persistent negative symptoms, fewer patients in the amisulpride group than in the placebo group dropped out; amisulpride and conventional antipsychotics did not differ for dropouts (table).

\section{Conclusions}

In patients with schizophrenia, amisulpride reduces symptoms and dropouts relative to placebo and reduces need for antiparkinsonian drugs relative to conventional antipsychotics. In acutely ill patients, amisulpride is more effective and leads to fewer dropouts than conventional antipsychotics
Amisulpride (Am) v placebo or conventional antipsychotics (CAPs) for schizophrenia*

\begin{tabular}{|c|c|c|c|c|}
\hline Outcomes & Patient group & Comparison & $\begin{array}{l}\text { Number of } \\
\text { studies }\end{array}$ & $\begin{array}{l}\text { Effect size } \\
r(95 \% \text { CI }) \dagger\end{array}$ \\
\hline \multicolumn{5}{|c|}{$\begin{array}{l}\text { Mean change in } \\
\text { BPRS score } \\
\text { from baseline Acutely ill }\end{array}$} \\
\hline \multirow[t]{3}{*}{$\begin{array}{l}\text { Mean change in } \\
\text { negative } \\
\text { symptoms }\end{array}$} & $\begin{array}{l}\text { Persistent, } \\
\text { predominantly } \\
\text { negative symptoms }\end{array}$ & $\begin{array}{l}\text { Am } v \\
\text { placebo }\end{array}$ & 4 & 0.26 (0.19 to 0.34$)$ \\
\hline & & Am $v$ CAPs & 3 & $0.08(-0.12$ to 0.26$) \neq$ \\
\hline & Acutely ill & Am $v$ CAPs & 5 & $0.14(0.08$ to 0.19$)$ \\
\hline \multirow[t]{2}{*}{$\begin{array}{l}\geqslant 1 \text { dose of AP } \\
\text { drugs }\end{array}$} & Not specified & $\begin{array}{l}\text { Am } v \\
\text { placebo }\end{array}$ & 4 & $0.01(-0.08$ to 0.22$) \neq$ \\
\hline & & Am $v$ CAPs & 12 & 0.25 (0.17 to 0.32$)$ \\
\hline \multirow[t]{3}{*}{ Dropouts } & Acutely ill & Am $v$ CAPs & 11 & $0.17(0.08$ to 0.26$)$ \\
\hline & $\begin{array}{l}\text { Persistent, } \\
\text { predominantly } \\
\text { negative symptoms }\end{array}$ & $\begin{array}{l}\text { Am } v \\
\text { placebo }\end{array}$ & NR & $0.20(0.12$ to 0.28$)$ \\
\hline & & Am $v$ CAPs & 3 & $0.08(-0.08$ to 0.23$) \neq$ \\
\hline
\end{tabular}

${ }^{\star} \mathrm{AP}=$ antiparkinsonian; $\mathrm{NR}=$ not reported. $\mathrm{Cl}$ defined in glossary. $†$ Positive values show benefit for amisulpride. tNot statistically significant.

\section{COMMENTARY}

Amisulpride warrants particular attention because its pharmacological profile is clearly distinct from other currently available atypicals. Other atypicals have greater serotonin 5-HT ${ }_{2}$ versus dopamine $\mathrm{D}_{2}$ antagonism, ${ }^{1}$ whereas amisulpride has no effects on the serotonin $5-\mathrm{HT}_{2}$ system.

Amisulpride, like risperidone, has a risk of EPS that is dose dependent and evident at high therapeutic doses. Another similarity to risperidone is the risk of elevated prolactin. Amisulpride's superiority in acute psychosis for global and negative symptoms when compared with conventional antipsychotics must be qualified. These studies have routinely used conventional antipsychotic doses equivalent to $\geqslant 12 \mathrm{mg} /$ day of haloperidol. Another meta-analysis showed that differences can be eliminated when comparisons with more appropriate doses are made. ${ }^{2}$ This caution in interpreting differences is relevant not only for negative symptoms but also for total scores. Again, this critique is not just levelled at amisulpride but at all studies that compare newer antipsychotics with excessive doses of conventional agents.

Amisulpride's superiority in patients with predominantly negative symptoms was seen in placebo controlled trials but not in the limited available comparisons with conventional antipsychotics. Insufficient data exist to indicate whether this is because of a unique superiority of amisulpride or the absence of data for other drugs in this group of patients.

In so far as amisulpride provides antipsychotic activity with low EPS, it, like others, is an atypical. As noted above, this conclusion is tempered by the high dose of comparison drugs. Any definitive statement regarding superior efficacy is made more difficult by the fact that the benefits are modest, and definitive trials in refractory patients have not been done (clozapine is the only drug with clear benefits in this segment). What is striking is that despite having a different pharmacology, the clinical profile is nearly indistinguishable from some of the newer atypicals. This not only makes amisulpride an interesting drug clinically, but may also elucidate much about the mechanism of what we now call atypicality.

Gary Remington, $\mathrm{MD}, \mathrm{PhD}, \mathrm{FRCP}(\mathrm{C})$ Shitij Kapur, MD , PhD, FRCP (C) University of Toronto, Toronto, Ontario, Canada

1 Kapur S, Remington G. Atypical antipsychotics: new directions and new challenges in the treatment of schizophrenia. Аппи Rev Med 2001;52:503-17.

2 Geddes J, Freemantle N, Harrison P, et al. Atypical antipsychotics in the treatment of schizophrenia: systematic overview and meta-regression analysis. BMJ 2000;321:1371-6. http://ebmh.bmjjournals.com/cgi/content/full/4/3/77 